\title{
Quantifying Environmental Impacts of Temporary Housing at the Urban Scale: Intersection of Vulnerability and Post- Hurricane Relief in New Orleans
}

\author{
Claire McConnell ${ }^{1} \cdot$ Chiara Bertolin $^{2}$
}

Published online: 20 December 2019

(C) The Author(s) 2019

\begin{abstract}
The increasing risk and exposure of people and assets to natural hazards and disasters suggests an increasing need for temporary housing following disasters. Resilience to natural hazards is dependent on the resources available to families or communities to prepare for and mitigate risk, influenced by social vulnerability. This study seeks to quantify the total environmental impact of temporary housing deployment in New Orleans, using the catastrophic impact of Hurricane Katrina in southern Louisiana in August 2005 as a case example. We employ a novel approach to estimate displacement period and take into account social vulnerability across New Orleans neighborhoods to better understand the scale of post-disaster relief and its global warming potential. The methodology implemented in this study comprises three steps: a risk assessment, a life cycle assessment, and a resulting total impact assessment. We demonstrate the considerable risk of greenhouse gas emissions and energy impacts from temporary housing deployment linked to hurricane hazard. Furthermore, we show that environmental impact is highly sensitive to displacement period and find the current methodology of anticipating temporary housing use by hazard alone to be inadequate. Additionally, the approach presented in this article provides tools to politicians and disaster risk professionals that allow for resource
\end{abstract}

Claire McConnell

claire.e.mcconnell.15@gmail.com

1 Department of Architecture and Technology, Norwegian University of Science and Technology (NTNU),

7491 Trondheim, Norway

2 Department of Mechanical and Industrial Engineering, Norwegian University of Science and Technology (NTNU), 7491 Trondheim, Norway investment planning to decrease social vulnerability, thus enhancing resilience and adaptive capacity in a more homogeneous way at the urban scale.

Keywords Disaster risk - Global warming potential $\cdot$ Hurricane Katrina $\cdot$ Life cycle assessment $\cdot$ New Orleans $\cdot$ Social vulnerability · Temporary housing

\section{Introduction}

The increasing risk and exposure of people and assets to natural hazards and disasters due to population growth, skewed development, and a changing climate suggests increasing need for temporary housing $(\mathrm{TH})$ following disasters. The scale and recurrent necessity of temporary housing and the acknowledged intensity of greenhouse gas (GHG) emissions from the built environment raise questions about the sustainability of temporary housing, in terms of both supply and environmental impact.

Providing adequate temporary housing for disaster victims in the months or years between hazard strike and reconstruction is the most substantial challenge faced by government officials in disaster planning (US DHS and FEMA 2009). Empirical research has shown that temporary housing use often lasts longer than is initially expected or planned for, and is most often occupied by populations of high social vulnerability including low income families and the elderly (Elliot and Pais 2006; Johnson et al. 2006).

Resilience to natural hazards is the collective strengths, attributes, and resources available to families or communities to prepare for and mitigate risk, influenced by disparities and deficiencies in social demographics, that is, social vulnerability (IPCC 2014). Temporary housing use 
is naturally a function of social demographics, as more resilient (less socially vulnerable) communities are better able to absorb losses, and therefore are faster to recover and less likely to need temporary housing. This is antithetical to current metrics of displacement from natural hazard-induced disasters; the US Federal Emergency Management Agency (FEMA), for example, assigns expected displacement periods based solely on structural damage as a surrogate for hazard intensity (US DHS and FEMA 2015). We observe a lack of methodology to accurately assess temporary housing occupancy that includes social vulnerability.

The Federal Emergency Management Agency acknowledges that the traditional strategies for temporary housing-for example, mobile homes, manufactured homes, and rented apartments - are not adequate, and that new and innovative approaches are required to meet demand (US DHS and FEMA 2009). Recent work in the fields of disaster risk management and resilience has sought to identify the temporary housing strategies most effective in providing post-disaster relief. In particular, researchers have proposed the use of a holistic, multicriteria model for evaluating temporary housing (Hosseini 2016; Ismail et al. 2017; Hennequin et al. 2018). Although there is a range of potential variables to be considered, it is generally recognized that disaster management strategies effective at building resilience are those that strengthen social-ecological systems (Colten et al. 2008; Gotham and Campanella 2011, 2013; Ismail et al. 2017).

Previous work has sought to reduce the environmental impact of temporary housing, focusing mainly on reuse and recycling at the end of occupancy (Arslan 2007; Arslan and Cosgun 2008) and analyzing environmental indicatorsenergy demand and global warming potential (GWP) in particular-embodied in the materials used in construction through life cycle assessment (Tucker et al. 2014; Atmaca and Atmaca 2016; Islam et al. 2016; Song et al. 2016; Atmaca 2017; Ismail et al. 2017). However, there is a gap in the literature in analyzing environmental impact beyond an individual temporary housing unit. As far as we know, there has yet to be a study quantifying the total environmental impact of temporary housing at the municipal or regional scale.

This study seeks to quantify the total environmental impact of temporary housing deployment in New Orleans in order to better understand the scale and significance of post-disaster temporary housing deployment. Specifically, we wish to study the implications of temporary housing use on GHG emissions (GWP) and energy demand and analyze sensitivity to displacement period. To do this, we: (1) evaluated temporary housing need from residential damage caused by hurricanes in New Orleans, taking social vulnerability into account in the estimation of displacement period; (2) assessed the environmental impact of temporary housing units using life cycle assessment (LCA); and (3) synthesized the results to estimate the impact at the municipal scale.

This article is intended for professionals in the field of disaster risk management, including politicians, researchers, planners, nongovernmental organizations, and others involved in planning and preparing for natural hazards. We aim to provide a framework for assessing temporary housing need and impact, and disaster risk management and mitigation strategies as a result of our analysis.

\section{Background}

The following sections summarize the main concepts and frameworks used in this article, and contextual background for understanding the theoretical application and assessment of a specific temporary housing strategy-retired shipping containers-for the representative case study of Hurricane Katrina and urban New Orleans.

\subsection{Risk and Life Cycle Assessment Frameworks}

Disaster risk is the probability of loss from the intersection of hazard-in the case of hurricanes, extreme wind speed-exposure and vulnerability. Risk assessment quantifies the level of risk that results from exposure of people and assets to a natural hazard in the context of local social vulnerability. Disaster risk management strategies aim to mitigate actual outcomes of natural hazards by reducing vulnerability and managing exposure (IPCC 2014).

Life cycle assessment is a tool for evaluating the environmental impacts of products with the purpose of understanding and reducing impacts to the environment (ISO 2006). The impact to specific environmental systems (for example, global warming potential) is assessed over 16 lifecycle phases, grouped generally into four stages: product manufacture (A1-A3), construction (A4-A5), use (B1-B7), and end of life (C1-C4). For a full life cycle assessment, the potential impacts are analyzed over the entire product life cycle, from raw material extraction to disposal following three steps: inventory compilation of product system inputs and outputs, assessment of the potential impacts of inputs and outputs, and interpretation of analysis results.

This study proposes the application of these frameworks to estimate and predict the environmental impact of temporary housing deployment to mitigate urban displacement in cities exposed to natural hazards and disasters. Specifically, we use the impact of Hurricane Katrina in New Orleans in 2005 as a case study. 


\subsection{Hurricane Risk in New Orleans}

New Orleans is chosen as a case study setting for analysis due to its exposure to hurricanes and characteristics inherent to the city that increase risk. These include steady population growth concurrent with environmental mismanagement through development of coastal wetlands; reliance on the levee system to protect an urban city with expanding infrastructure; and a society rooted in racial and socioeconomic divisions living in an area vulnerable to rising sea levels and extreme weather (Elliot and Pais 2006; Gotham and Campanella 2011, 2013; IPCC 2014).

Specifically, we use the case of Hurricane Katrina as a starting point for analysis, utilizing the widespread availability of data and previous work around risk, vulnerability, and recovery in New Orleans that was published in the wake of the storm. These resources-including neighborhood recovery rates and demographic breakdowns-are used in our proposed evaluation model to assess temporary housing need and the impact predicted for contemporary hurricane hazards.

Hurricane Katrina struck the Gulf Coast in August of 2005 and proved to be one of the costliest and most deadly hurricanes ever to hit the United States (Blake et al. 2011). Following the hurricane and massive flooding of New Orleans due to levee failures, the scale of post-disaster housing requirements proved larger than any previously seen in US history (Nigg et al. 2006). More than one million people were displaced from the state of Louisiana alone (Esri 2015), nearly half from New Orleans (Elliot and Pais 2006).

Community resilience and recovery from Hurricane Katrina has been widely studied. This research focuses on identifying and quantifying the contemporary social vulnerabilities that caused inequality in recovery (Colten et al. 2008; Gotham and Campanella 2011, 2013; Jordan et al. 2014). Elliot and Pais (2006) found race and socioeconomic status to be key indicators of the time it took communities to regain livelihoods. Moreover, Gotham and Campanella (2013) noted that African American residents comprised $76 \%$ of the population affected by deep flooding during Katrina, compared to only $20.6 \%$ of whites, and generally experienced increased geographic exposure to hurricane hazards. In their multifactor approach, Jordan et al. (2014) identified low social vulnerability generally and high economic capacity in particular as key factors that led to recovery, while high social vulnerability generally and low economic capacity in particular were significant barriers to recovery.

\subsection{Shipping Containers as Temporary Housing}

Given the goal of this study, which is to assess the broader implications of post-disaster temporary housing, we choose a temporary housing strategy proposed for its environmental benefit-retired shipping containers-to determine the "best-case-scenario" environmental impact of temporary housing deployment. Standardization in the shipping industry and the extensive global use of cargo container units has resulted in worldwide supply and distribution potential of construction-strength containers (Peña and Schuzer 2012). For this reason, the use of shipping container construction-intermodal steel building units (ISBU) - in disaster relief has been explored as an efficient strategy for providing low cost, transportable, adaptable, and flexible temporary housing units (Christensen and Worzala 2010; Peña and Schuzer 2012; Zhang et al. 2014; Atmaca and Atmaca 2016; Islam et al. 2016; Atmaca 2017). Moreover, ISBU housing has been found to be significantly cheaper than traditional prefabricated units (Atmaca and Atmaca 2016).

Environmental benefits of using ISBU containers are potentially compounded in recovery applications by reduced global energy costs associated with container disposal and local resource consumption in the short term for temporary housing construction and over the long term in applications where temporary housing strategies plan for reuse or adaptation as permanent housing.

Some literature exists that evaluates the life cycle of shipping containers as disaster relief units (Islam et al. 2016; Song et al. 2016; Atmaca 2017). Research shows simple modifications to the existing container structure can produce a unit with a high performing envelope that contributes to a significantly smaller carbon footprint and environmental impact (Fuller 2006). Similarly, Atmaca (2017) finds that ISBUs have a smaller environmental impact per capita than prefabricated units, a typical baseline construction.

Overwhelmingly, the literature cites operational energy as the most significant source of total environmental impact for both container units and prefabricated units (Atmaca and Atmaca 2016; Islam et al. 2016; Atmaca 2017). The fuel source for operational energy demand has been acknowledged as a significant factor in the environmental impact of temporary housing (Atmaca and Atmaca 2016; Ismail et al. 2017), made more relevant in the case of ISBUs, where shipping container reuse reduces the impact of material use in construction. The building elements with the largest relative contribution to environmental impact are identified as the roof and foundation (Atmaca 2017). 


\section{Methods}

The novel methodology implemented in this study allows an innovative temporary housing assessment framework in which risk is tied to environmental impact. This proposed framework is comprised of three phases: a risk assessment, a life cycle assessment, and a resulting total assessment. First, a risk assessment of major hurricane events in New Orleans is conducted, resulting in estimations of the required number and duration of use of ISBU quality temporary housing units related to hazards of varying intensity. The displacement period during which temporary housing is used is estimated at the neighborhood scale, relative to the social vulnerability of the local population. Second, a simplified life cycle assessment is conducted to estimate the global warming potential and energy demand of the construction and use of a single-family temporary housing ISBUs. Finally, the results of the risk assessment and life cycle assessment are synthesized to examine the citywide global warming potential risk of temporary housing following hurricanes in New Orleans and the spatial distribution of global warming potential intensity across neighborhoods of the city.

\subsection{Risk Assessment to Determine Temporary Housing Need}

In the risk assessment phase of our methodological approach, hazard is identified using seven hypothetical hurricane storm events, proxied by the low, median, and high maximum sustained wind speeds categorizing major hurricanes on the Saffir-Simpson scale. Secondary hurricane hazards such as storm surge-out of the scope of this study-are not considered due to a lack of research into damage potential of secondary hazards and uncertainty in how compounding hazards affect temporary housing need and displacement period. In our approach we estimate, for each of the seven hazard intensities, the residential building stock at risk across New Orleans neighborhoods. The number of temporary housing units required for each neighborhood following each hazard event is taken as the number of residences suffering severe structural damage or destruction. This value is estimated using statistical damage probabilities and municipal building stock data (US DHS and FEMA 2015).

We adopt the damage potential curves defined by FEMA to estimate the probability of damage-no damage, minor damage, moderate damage, severe damage, and destruction-to a building type as a function of maximum sustained wind speed. Our assumption at this stage of the calculation is to consider only residences predicted to be severely damaged or destroyed, such that displacement is longer than 6 months, warranting temporary housing use and deployment (Quarantelli 1995; US DHS and FEMA 2015).

One novelty of our approach is the detailed assessment of the displacement period based not only on the severity of damage as practiced by FEMA (US DHS and FEMA 2015), but also on relative measures of local social vulnerability. A simplified Social Vulnerability Index (SoVI) methodology, which uses 28 of the over 42 variables considered by Cutter et al. (2003) is employed to evaluate disparities across New Orleans neighborhoods. The normal distribution is applied to the SoVI results to determine ranges of low, average, and high social vulnerability in order to broadly categorize adaptive capacity in the neighborhoods. Levels of social vulnerability are compared to post-Katrina recovery data to evaluate displacement period-or recovery time. Following the methodology of Finch et al. (2010), displacement period is assumed to be the number of years between Hurricane Katrina and the point at which $90 \%$ of pre-Katrina residences are receiving mail.

This approach is novel in its application of Finch et al.'s (2010) methods to social vulnerability analysis. One limitation of this study is attributing displacement periods to wind hazard, given that the effect of storm surge and levee failures cannot be uncoupled. Actually, this is the most robust data for assessing displacement period across New Orleans known to the authors, and although there is potential to overestimate displacement period and thus environmental impact, the data still serves the goals of the overall study in evaluating environmental impact based on temporary housing need.

\subsection{Life Cycle Assessment to Determine Emissions Impact of Temporary Housing}

The second phase in our methodological approach is to apply a simplified life cycle assessment to ISBU quality temporary housing. The scope of the simplified life cycle assessment includes only material use (A1-A3, B1-B2, and B4 stages) and operational energy for space conditioning (limited B6 stage). Energy inputs to ISBU modification and unit erection (A4-A5, B3, and B5 stages) and demolition and disposal (C1-C4 stages) are not quantified.

The ISBU design evaluated in this study is based on the floor plan and technical specifications presented by Peña and Schuzer (2012), apart from the foundation system, the substitution of plasterboard for drywall, and with additional insulation added to the roof. Technical specifications are summarized in Table 1 with replacement periods for material use over the unit lifespan, assumed to be 60 years after modifications for habitability. Electrical wiring, plumbing, furniture, appliances and equipment, and energy 
Table 1 Material use and maintenance requirements of temporary intermodal steel building units

\begin{tabular}{lll}
\hline Building component & Material & Material lifespan years/number of replacements) \\
\hline Structure & Steel tube reinforcement for structural modification & 60 \\
Foundation & $20 \mathrm{~cm}$ reinforced concrete slab foundation & $60^{*}$ \\
Roof & $127 \mathrm{~mm}$ closed-cell polyurethane spray foam insulation & 60 \\
& Galvanized steel studs & 60 \\
& $10 \mathrm{~mm}$ plasterboard & $15 /(3)$ \\
Walls & $63.5 \mathrm{~mm}$ closed-cell polyurethane spray foam insulation & 60 \\
& Galvanized steel studs & 60 \\
Floor & 10 mm plasterboard & $15 /(3)$ \\
Windows & 28.5 mm plywood flooring & $30 /(1)$ \\
Paint) & Aluminum-framed, 6 mm double glazing & 60 \\
\hline
\end{tabular}

*Indicates material inputs are for useful life

used during occupancy for uses other than space conditioning are excluded from the life cycle assessment system boundary.

In our methodological approach, we assumed the temporary ISBU structures will not be disposed of after a single use but saved for future disaster relief applications, a noted benefit of their use. Therefore, to reflect flexibility over the lifespan of the ISBU, our approach proposes a novel variable over which to conduct the life cycle assessment: the "useful life." We distinguish between lifespan and useful life, where temporary housing lifespan is measured from the first use to end of life, and the useful life coincides with the displacement period. An ISBU would therefore have more than one useful life over its entire lifespan.

Lifespan life cycle inputs consist of materials for container retrofit and maintenance. The lifespan global warming potential over the useful life is estimated by calculating the total impact per year and multiplying by the useful life. That is:

Lifespan global warming potential

$$
=\frac{\text { Total lifespan emissions }}{60 \text { year lifespan }} \times \text { Useful life }(\text { years })
$$

In effect, this allows the burden of lifespan material inputs to be shared by all users of the ISBU and quantifies the benefit of ISBU reuse in terms of lowering temporary housing energy demand and global warming potential over the useful life. A limitation to this approach is the risk of underestimating actual impact any time the unit is unoccupied between users. This is a novel variable, as the deployment of reusable temporary housing units is too recent a phenomenon for reliable data to be available on expected use.
Life cycle inputs accounted for in totality over the useful life of temporary housing are concrete foundations and paint-material inputs distinct to unit erection-and operational energy for space heating and cooling. Material quantities are calculated using the design specifications in Table 1 and multiplied by environmental indicator factors sourced from the Inventory of Carbon and Energy version 2.0 database (ICE 2011) to determine embodied energy and GHG emissions from module modification.

Annual operational energy demand is estimated from heating and cooling degree days as presented by the Chartered Institute of Building Service Engineers (CIBSE 2006). Degree days are assumed to be constant for the purposes of this study and are calculated from historical temperature data produced by NASA/GISS (2014) for the Coupled Model Intercomparison Project, Phase 5 (CMIP5) coordinated by the World Climate Research Programme (WCRP). The power source for heating and cooling is assumed to be a diesel generator, a common source of electricity in temporary housing camps (Peña and Schuzer 2012). The emission factor for liquid diesel fuel is assumed to be $0.06,934$ ton $\mathrm{CO}_{2} \cdot \mathrm{GJ}^{-1}$ (IEA 2012).

The total environmental impact of a single relief use of an ISBU is assessed as the sum of the material inputs of container retrofit over the displacement period, material inputs for ISBU erection, and the energy demand for space conditioning over the displacement period. These totals are combined with the total number of ISBUs required and the spatial distribution of social vulnerability as determined by the methods in Sect. 3.1 to estimate the total impact of temporary housing relief for the seven varying hazard intensities. 


\subsection{Totaling the Impact of Hurricane Relief}

The final stage in our methodology synthesizes risk analysis and life cycle assessment to quantify the total global warming potential and energy demand of temporary housing deployment across New Orleans for hurricane events. The temporary housing need and impacts assessed by the methods presented in Sects. 3.1 and 3.2 are combined to scale the impact of temporary housing deployment, summing impact and assessing spatial distribution to determine intensity across the New Orleans neighborhoods. The environmental risk from ISBUs used as temporary housing after hurricane events is evaluated in this study by adopting a new methodological approach adapted from damage potential and annual risk density curves in the field of risk management.

First, an "impact potential" curve is constructed by plotting total, citywide life cycle impact as a function of hurricane return period, that is, the probability of occurrence. This quantifies expected global warming potential and energy demand for a given hurricane intensity. An annual "impact density" curve is then constructed from the product of the impact potential and hazard probability density curves. This quantifies the distribution of annual impact from temporary housing in response to hurricane events; integrating under the curve produces expected annual impact. The shape of the impact density curve also indicates characteristics of temporary housing impact in New Orleans and will be further explored in Sects. 4.3.1 and 5.1.

Finally, to see the effect of displacement period on environmental impact, two curves are plotted: (1) the impact calculated using displacement periods estimated from social vulnerability as previously described; and (2) the impact calculated using standard FEMA displacement periods based on hazard only.

The spatial distribution of the environmental impact intensity of temporary housing use is likewise an original method in this study. The total impact intensity in each neighborhood is calculated using the total respective number of required temporary housing units and the global warming potential and energy demand assessed over the respective displacement period. The relative environmental impact is mapped using ArcMaps.

\section{Results}

The following sections present the results of the three components of the study: (1) risk assessment, (2) life cycle assessment, and (3) synthesis. First, findings from the evaluation of risk across New Orleans are presented in terms of anticipated temporary housing need and effectiveness of temporary housing in post-disaster recovery time- that is, required number of ISBU and displacement period, respectively-in areas of New Orleans with different social vulnerability (Sect. 4.1). Then, the environmental impact at the scale of an individual ISBUdetermined through application of life cycle assessmentis reported in terms of global warming potential and energy demand for the scenario of a hurricane hazard of category 4 storm, comparable to Hurricane Katrina (Sect. 4.2). Moreover, this section evaluates the sensitivity of displacement period to hazard intensity and displacement period. Finally, temporary housing need (Sect. 4.1) and impact (Sect. 4.2) are combined to evaluate the environmental impact of temporary housing deployment at the municipal scale (Sect. 4.3).

\subsection{Temporary Housing Unit Need and Displacement Period}

To simplify calculations of risk to the residential building stock, the most common residential building types are evaluated such that roughly $75 \%$ of the total residential building stock is included in the analysis. We use FEMA's General Building Stock (GBS) database (US DHS and FEMA 2015) to quantify the relative percentage of residential buildings in each neighborhood by building type.

The number of ISBU required due to structural damage to residences is listed in Table 2 for each of the seven assessed hazard intensities. The number of temporary housing units required is found to increase rapidly as hazard intensities reach category 4 on the Saffir-Simpson scale. At wind speeds of category 5 storms, the majority of the building stock is effectively destroyed.

We identify 28 of the 42 SoVI variables listed by Cutter et al. (2003) as applicable to New Orleans in the evaluation of vulnerability. Additionally, three supplementary variables quantifying the mobile home stock, the number of households lacking access to a vehicle, and international migration are introduced, chosen based on their inclusion in similar studies of social vulnerability (Myers et al. 2008; Burton 2010; Finch et al. 2010). Data are sourced from independent websites cataloguing US Census Bureau and American Community Survey statistics at the neighborhood level (City-data 2017; Data Center 2017).

The results of the modified SoVI analysis applied in our methodological approach show that socioeconomic status is the component with the largest contribution to spatial variance in vulnerability. Other factors found to have a relatively high impact on vulnerability include degree of exposure of people and assets, and households with higher levels of dependence, for example, the elderly, households without access to a vehicle, and renters. This is consistent with the literature. In total, these components explain 
Table 2 Number of temporary intermodal steel building units needed in New Orleans following hurricane hazards of a given intensity

\begin{tabular}{llcc}
\hline Wind speed $(\mathrm{km} / \mathrm{h})$ & Storm category & ISBUs & Damaged residences compared to total $(\%)^{*}$ \\
\hline 178 & 3 & 11,394 & 6.0 \\
193 & 3 & 34,941 & 18.4 \\
208 & $3 / 4$ & 78,048 & 41.1 \\
230 & 4 & 123,243 & 64.9 \\
250 & $4 / 5$ & 167,489 & 88.2 \\
275 & 5 & 185,149 & 97.5 \\
290 & 5 & 187,618 & 98.8 \\
\hline
\end{tabular}

ISBU Intermodal steel building unit

${ }^{*} 75 \%$ of residential building stock

$78.35 \%$ of the variation across the neighborhoods in the city.

Three neighborhoods are identified based on the modified SoVI analysis as representative of a typical low, average, and high vulnerability neighborhood: Lower Garden District, Mid-City, and Desire Area, respectively. The displacement periods estimated from Hurricane Katrina recovery data for these neighborhoods are 1.33 years, 4.67 years, and 10 years, respectively. The relative increase in recovery time with evaluated neighborhood vulnerability supports arguments for the connection between social vulnerability and temporary housing use identified in the reviewed literature. The estimated displacement periods are applied universally to all neighborhoods falling in the respective ranges of low, average, and high vulnerability in the calculation of the results presented in Sects. 4.2 and 4.3. It is notable that the estimated displacement periods indicate temporary ISBU housing reuse is feasible. Even in areas of high social vulnerability, ISBUs could be used up to six times over their lifespan.

The displacement periods estimated following our methodological approach using a modified SoVI analysis show a significant difference to the displacement periods used by FEMA. The use of temporary housing in areas of low social vulnerability is comparable to the maximum 1-year displacement period estimated by FEMA for destroyed residences. However, for the majority of New Orleans neighborhoods, the indicated need for temporary housing is significantly longer. Section 4.3 demonstrates the broader environmental impact implications of this discrepancy.

\subsection{Environmental Impact of Temporary Housing Deployment}

First, we discuss the results of the simplified life cycle assessment at the scale of an individual unit, contrasting the relative contributions of material use and energy for space conditioning during occupancy to total ISBU impact. Next, we determine the total impact at the urban scale and evaluate the sensitivity of displacement period calculated following our methodological approach and using-as comparison-standard FEMA rates. To simplify discussion, we show the results for a single hurricane hazard, choosing a category 4 storm, illustrative of wind hazard comparable to that documented during Hurricane Katrina.

\subsubsection{Impact of ISBU Material Use and Space Conditioning}

The results of the simplified life cycle assessment of an individual ISBU are shown in Fig. 1, calculated for households of low, average, and high social vulnerability. Operational energy use causes the majority of total global warming potential, at least in the New Orleans climate and when energy is supplied by a diesel generator, as is often the case in temporary housing camps. Annual emissions from space conditioning alone is nearly half the total material emissions (total lifespan). The displacement period then significantly affects the impact of ISBU temporary housing use. The global warming potential in areas of high and average social vulnerability are 5.5 and 2.7 times that estimated for areas of low social vulnerability, respectively. Differences in energy demand impact are of similar magnitudes.

The impacts of material use for ISBU containers vary less significantly with displacement period than operational energy, due to the high relative contribution of reinforced concrete in the container's foundation to overall material 

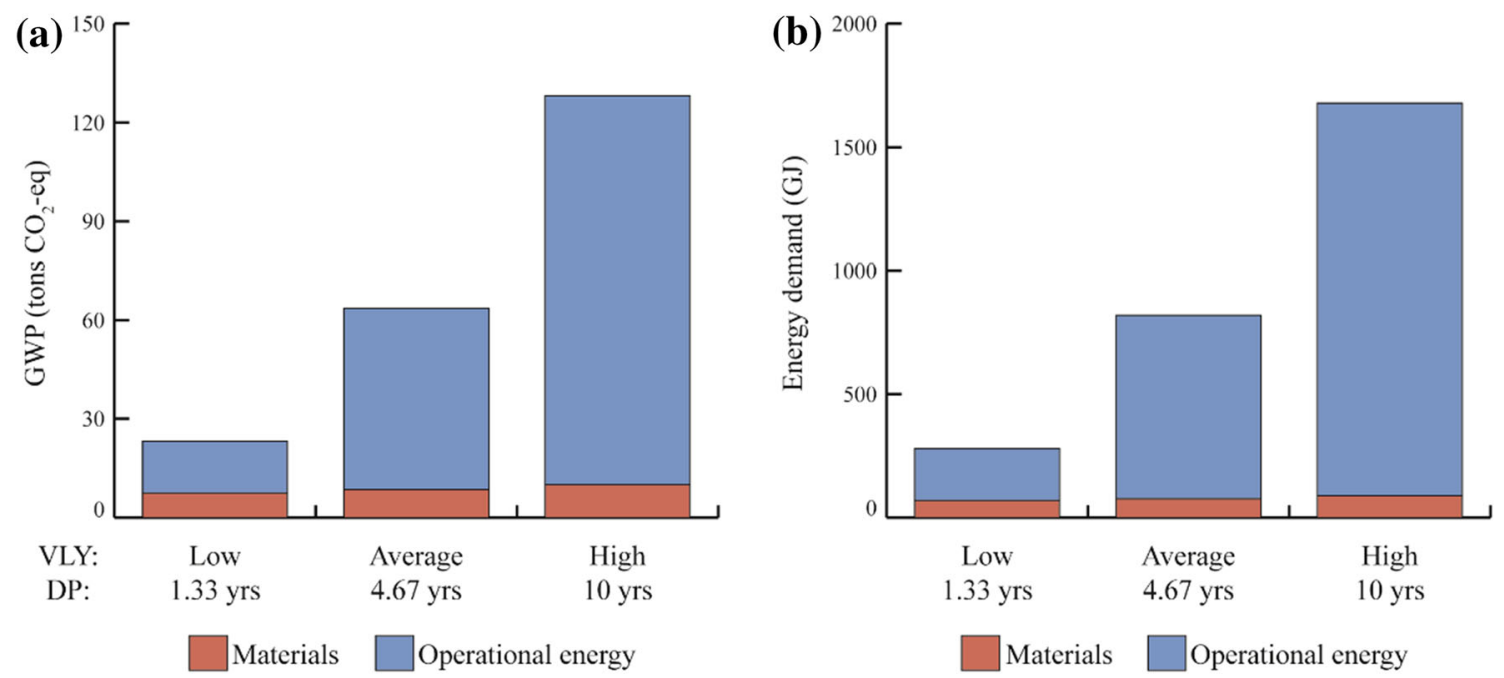

Fig. 1 Global warming potential (GWP) (a) and energy demand (b) of a single temporary housing intermodal steel building unit by relative social vulnerability. VLY: vulnerability; DP: displacement period
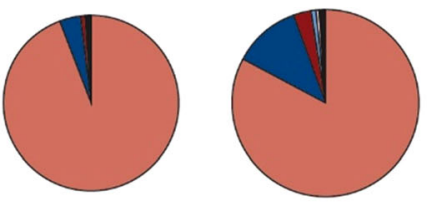

Low

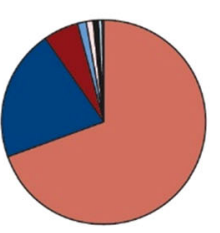

High

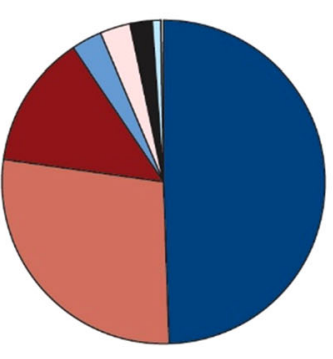

Reuse

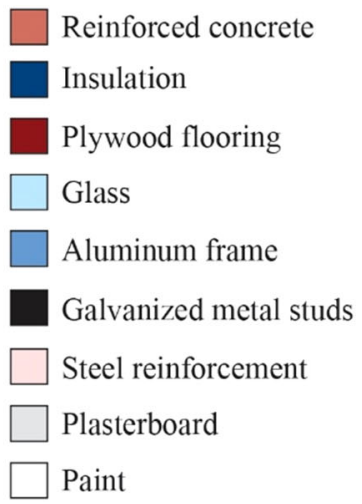

Fig. 2 Breakdown of material use global warming potential by relative social vulnerability, with material impacts assuming an intermodal steel building unit is reused and occupied its full lifespan (large pie diagram shown for comparison)

impacts, as shown in Fig. 2. Following our useful life cycle methodology, lifespan emissions per year of use are a relatively low fraction of the impact compared to the reinforced concrete foundations. Over the entire lifespan of an ISBU reuse, insulation causes nearly half the total impact, surpassing reinforced concrete.

Over a temporary housing unit's entire lifespan, assuming that only one ISBU erection occurs because the unit is reused continuously in place, insulation causes roughly $50 \%$ of the total global warming potential for material use, compared to approximately $30 \%$ by reinforced concrete. However, when considering multiple uses over the temporary housing unit lifespan, the impact of reinforced concrete foundations quickly rises, both in terms of absolute global warming potential and impact relative to material use for container modification. This suggests efforts to revise the design to minimize use of reinforced concrete foundations are the most efficient strategy to reduce ISBU material impacts. As the total material impacts for container modification over the unit's lifespan are more than twice that of ISBU erection, we conclude temporary housing reuse is significant to minimizing the material impacts of temporary housing deployment. Further studies on the life cycle impacts of different temporary housing construction types could indicate the magnitude of global warming potential and energy savings from temporary housing reuse over a unit's lifespan.

\subsubsection{Impact of Hazard Intensity and Sensitivity of Displacement Period}

Total environmental impact of temporary housing deployment city-wide is shown in Fig. 3 for a range of hurricane hazards, scaling the impact of a single ISBU by temporary 

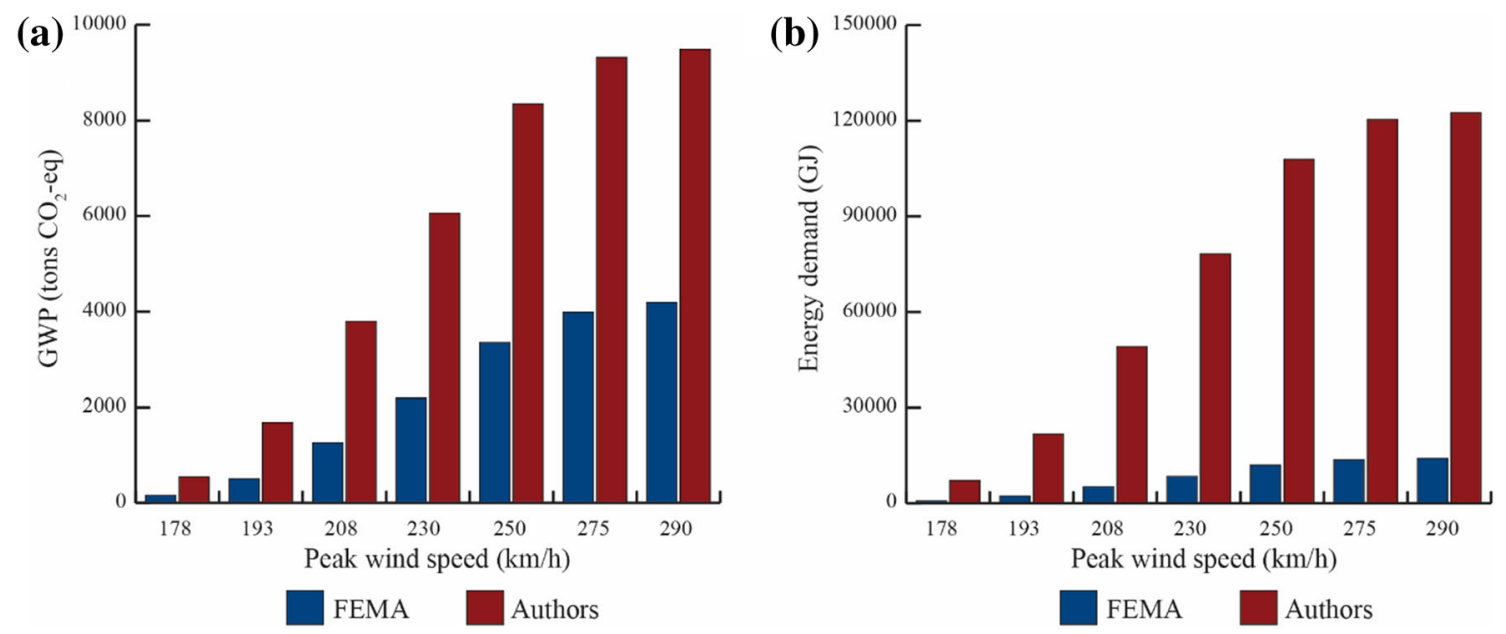

Fig. 3 Total environmental impact standard (US DHS and FEMA 2009) and as calculated by the Authors global warming potential (GWP) (a) and energy demand (b) of temporary housing deployment in New Orleans for varying hurricane intensities

housing need as presented in Table 2. Results are calculated using displacement periods estimated following our modified SoVI methodological approach and using standard FEMA displacement rates based on hazard alone. As visible, the magnitude of impact is considerable. Following our methodological approach, a category 4 storm of median intensity (peak wind speeds of $230 \mathrm{~km} / \mathrm{h}$ ) results in an impact over $20 \%$ of the total estimated residential energy use in the entire state of Louisiana in 2015 (EIA 2018).

The generic displacement periods assigned by FEMA are not precise enough to reflect the social vulnerability context and associated risk in New Orleans. In fact, even the larger of the two displacement periods (that is, 720 days for destroyed residences) is less than half the useful life approximated for the New Orleanian household of average social vulnerability. The total energy demand and global warming potential calculated using a modified SoVI methodology are more than double that predicted by FEMA displacement periods and approach 10 times greater in energy impact. An accurate metric of displacement period is therefore critical to evaluating the global warming potential of temporary housing use.

\subsection{Cumulative Impact of Citywide Temporary Housing Relief}

Section 4.3 synthesizes the individual results of the risk assessment and life cycle assessment to evaluate global warming potential and energy demand of temporary housing deployment at the municipal scale. Results are presented for ISBU temporary housing in New Orleans using both FEMA standard displacement periods and the author-calculated displacement periods evaluated in the previous section. Then the more impacting districts are also assessed.

\subsubsection{Environmental Risk of Temporary Housing Following Hurricanes in New Orleans}

The global warming potential and energy demand potential curves are shown in Fig. 4a and $\mathrm{b}$ with lines of best fit and the range of return periods corresponding to Saffir-Simpson category 3, 4, and 5 storms. Mirroring the trend in temporary housing requirements calculated in Sect. 4.1, total impact increases rapidly through category 3 and 4 hurricane hazards, when a marginal increase in peak wind speed significantly inflates the number of residences experiencing severe structural damage or destruction, and levels off at higher hazard intensities, when the majority of the building stock is severely damaged or destroyed during any storm.

The annual impact density curves are also shown in Fig. $4 \mathrm{c}$ and $\mathrm{d}$ with lines of best fit and the range of return periods corresponding to Saffir-Simpson category 3, 4, and 5 storms. Risk management principles ${ }^{1}$ indicate that the area under these curves is the expected impact cost in terms of global warming potential or energy use. Determining the area under the curve from the first data point to the return period for the hazard intensity in question results in the total expected impact as summarized in Fig. 4a and b.

The shape of the curve is attributed to increasing potential impact and decreasing probability of occurrence with hazards of higher intensity. Occurrences of category 3 and weaker category 4 storms - with impact densities near the peak-are more likely to occur in any given year but result in a smaller environmental impact from temporary housing deployment than stronger category 4 or category 5

\footnotetext{
${ }^{1}$ Risk density is equal to the product of hazard probability, exposure, and sensitivity (that is, of a building, area, district, social component, and so on) over capacity (that is, recovery capacity). The product of exposure by sensitivity over capacity is vulnerability (that is, the consequences of the impacts).
} 


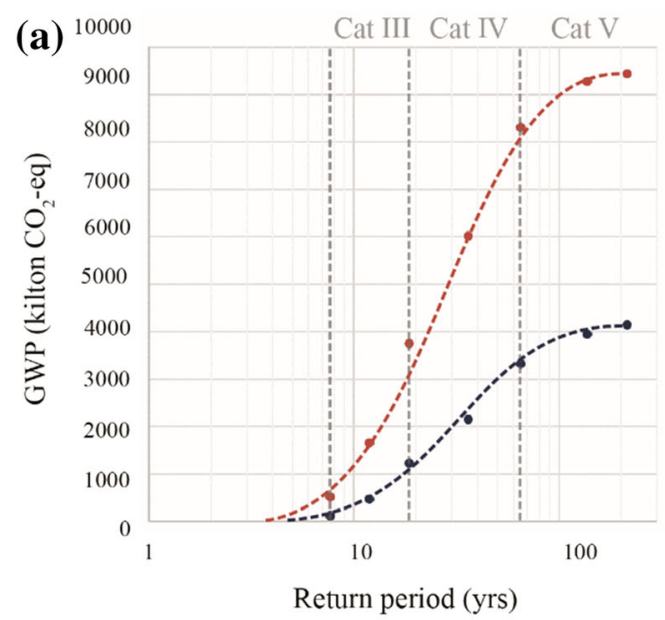

FEMA

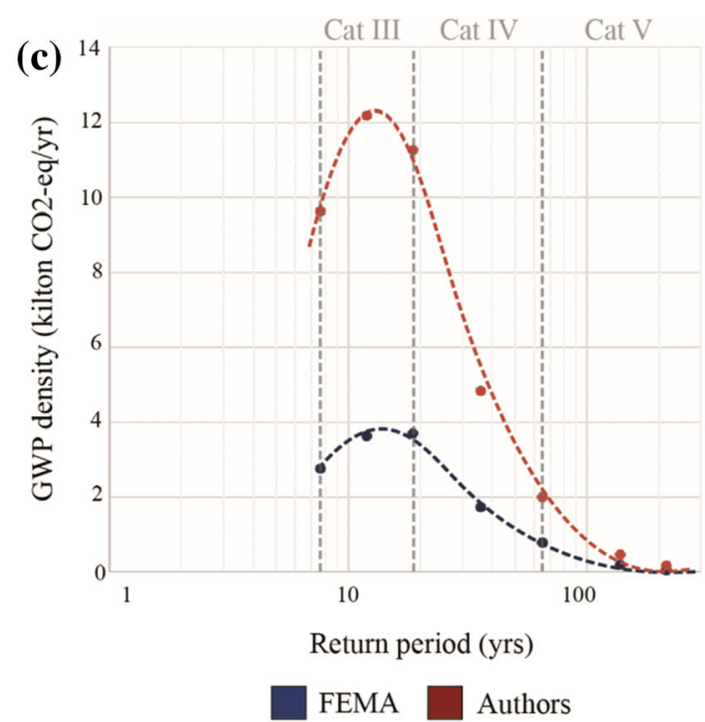

Fig. 4 Impact potential curves (a, b) and annual impact density curves (c, d) for global warming potential (GWP) and energy demand for intermodal steel building units temporary housing in New Orleans

storms with longer return periods. Similarly, the influence of incremental changes in return period on total impact peaks for category 4 storms, after which increases in hazard intensity result in modest changes in impact due to the extent of predicted structural failure of the residential building stock.

Paralleling results presented in Sect. 4.2, both the impact potential and impact density curves suggest the total environmental impact is highly sensitive to displacement period, most notably for energy demand. The annual impact density at the peak of the curve increases by a factor of eight between the FEMA standard and the approach defined in this study for energy demand, while global warming potential roughly triples. This shift in curve shape is significant to both the predicted impact of each hurricane

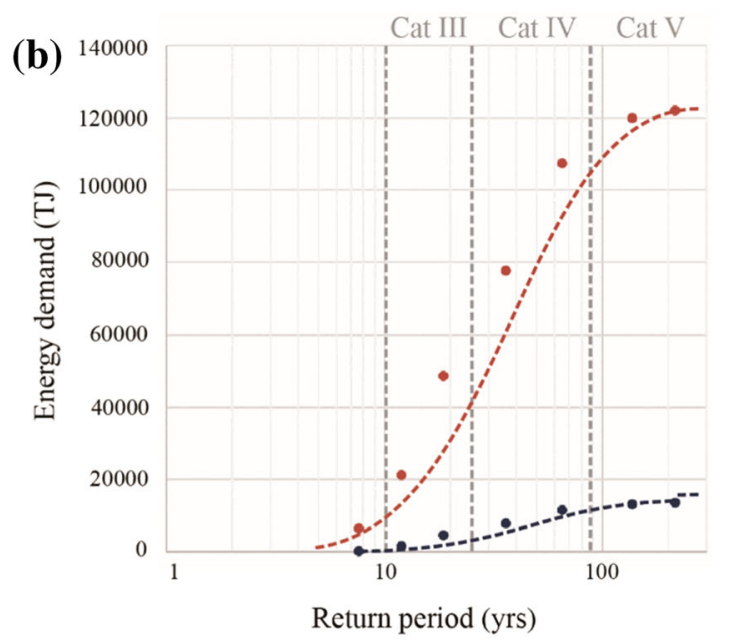

FEMA $\square$ Authors

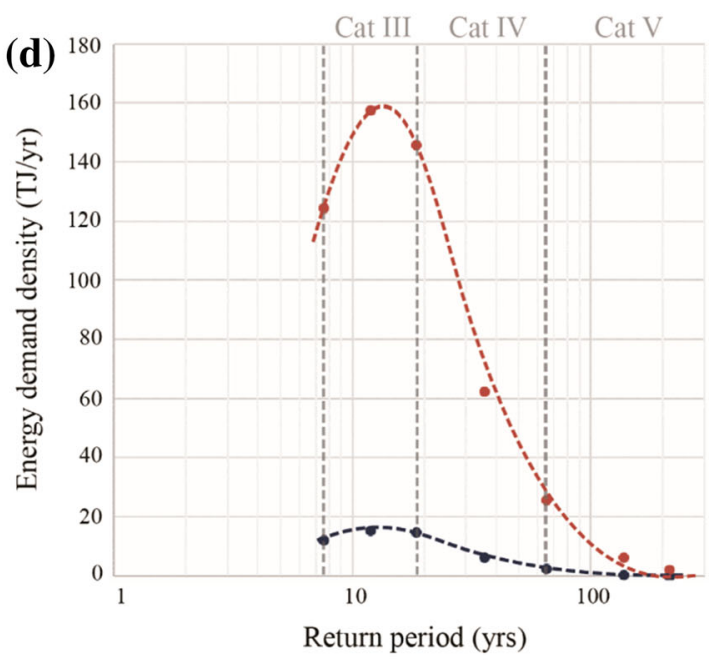

FEMA $\square$ Authors

using Federal Emergency Management Agency (FEMA) standardand Author-calculated displacement periods

event, and the long-term effects of compounding storm events.

\subsubsection{Relative Impact Intensity of Temporary Housing Across New Orleans}

Figure 5 maps the spatial distribution of global warming potential across New Orleans neighborhoods due to ISBU temporary housing deployment following a category 4 hurricane of median intensity $(230 \mathrm{~km} / \mathrm{h}$ wind speed hazard). Neighborhoods of higher social vulnerability are also neighborhoods with a greater relative global warming potential from temporary housing, with the exception of areas with significantly lower population density. This is expected based on the results previously presented, and 


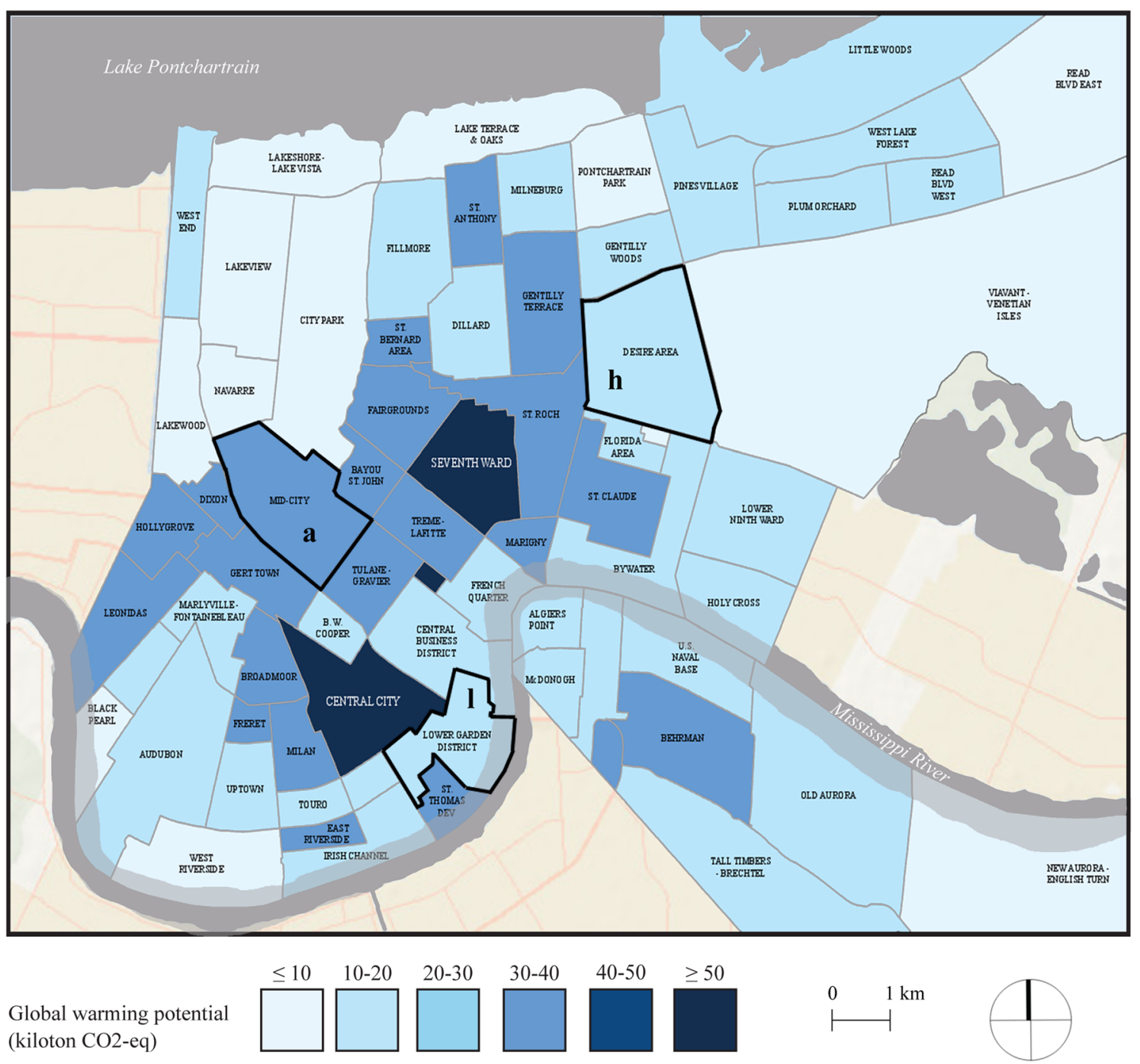

Fig. 5 Distribution of global warming potential across urban New Orleans neighborhoods from temporary housing deployment following a category 4 hurricane. Three neighborhoods have been identified as representative of low (1), average (a), and high social vulnerability (h)

visually confirms that social vulnerability greatly affects the environmental impact of temporary housing deployment.

The three neighborhoods representative of low, average, and high social vulnerability are marked in Fig. 5. MidCity (average vulnerability) has a higher global warming potential than Lower Garden District (low vulnerability). Desire Area, identified as high vulnerability, is an example of the exception noted above: environmental impact is lower relative to Mid-City and Lower Garden District, but population density is one-fifth and less than half, respectively.

\section{Discussion}

This study has demonstrated considerable risk of global warming potential and energy impacts from temporary housing deployment linked to hurricane hazard. There are additional global warming potential and energy implications for other construction activity directly linked to hurricane impact including cleanup and disposal of debris, infrastructure repair, and replacement and rebuilding of residential and commercial structures. Therefore, the results presented in this study total only a slice of the environmental impact of hurricanes and other destructive natural hazards and disasters. This study quantifies a temporary housing solution that results in a "best-case-scenario" in terms of environmental impact. We hypothesize the global warming potential and energy demand from other temporary housing construction types to be higher, 
especially when considering reuse, for example over a 50 -year disaster planning cycle. Future studies could replicate the methodology presented in this article for other temporary housing construction types to assess the relative impact of temporary housing unit designs.

Furthermore, we show that environmental impact is highly sensitive to displacement period. We find the current methodology of anticipating temporary housing use by hazard alone to be inadequate in the context of recent literature, which identifies social vulnerabilities as significant to estimations of temporary housing need. In addition to accurately anticipating environmental impact, accurate estimations of displacement period are paramount to anticipating temporary housing need. Although the ISBU offers potential benefits to temporary housing deployment and disaster risk planning, an adequate stock or reliable supply cannot be established if there is not an accurate methodology for estimating temporary housing need. The following sections explore these results in the broader contexts of climate change and potential applications in the field of disaster risk management.

\subsection{Anticipating Adjustment in Temporary Housing Need from Hurricane Activity Under Future Climate Change Scenarios}

The ability to project temporary housing need using the framework presented in this study under future climate change is invaluable to anticipating and preparing for future hurricane disaster scenarios in New Orleans and elsewhere for several reasons. At the most basic, temporary housing need assessment assists in the preparedness of communities or districts in a city against future severe weather events. Similarly, it allows adequate temporary housing to be secured at the district or urban scale under a range of warming scenarios depending on allowable risk tolerance. Moreover, the projected need and impact can be evaluated following the implementation of proposed risk management strategies. This point is especially significant, as risk and adaptive capacity function as feedback loops: strategies that increase adaptive capacity (for example, lowering social vulnerability or, at least, providing adequate temporary housing) bolster resilience and a community's ability to prepare for and respond to future disasters. Likewise, decreased resiliency (for example, from increased exposure or higher social vulnerability) makes recovery harder, and reduces the likelihood that communities will be able to respond effectively to hazards in the future. Our methodology can be particularly effective in enhancing the preparedness capabilities at district and urban scales.

Additionally, the Intergovernmental Panel on Climate Change (IPCC 2014) states with high confidence that climate change poses a challenge to anticipating, evaluating, and communicating disaster risks, particularly the probabilities and consequences related to extreme events such as major hurricanes. In other words, climate change threatens to undermine risk management planning and mitigation efforts, in addition to increasing the environmental burden of hurricane events. The framework presented in this study allows politicians and stakeholders to assess preparedness in the face of expected disasters from anticipated climate change.

Regarding anticipated changes in hurricane activity due to climate change, the IPCC (2014) concludes it is more likely than not that an increase in hurricane storm intensity will occur under warming scenarios, due to rising sea surface temperatures from high GHG concentrations. The IPCC (2014) states it is likely that sea level rise from anthropogenic sources has led to changes in extreme coastal high-water levels and likewise contributes to future upward trends in storm surge patterns. The threat of more severe weather from climate change and the increasing exposure of people and assets to natural hazards as a result of population growth, discussed in the framework of our results, suggest increased need for temporary housing in the future. We predict this would correspond to a leftward shift in the impact density curve shown in Fig. 4, reflecting a reduction in storm return period as hurricane intensity increases, and an upward shift of the curve peak, as temporary housing need increases.

\subsection{Tools for Disaster Risk Management}

Two potential tools are identified in this study for policymakers, researchers, and professionals working in the field of disaster risk management. First, impact density curves can be used to assess the projected influence of risk management strategies through the change in shape of the curve, as indicated in Sect. 5.1. Lowering the impact density curve peak lowers the total impact in all hazard scenarios. In general, the shallower the graph, the smaller the environmental impact of temporary housing deployment. Therefore, this curve provides a useful tool for comparison between risk management strategies and solutions that target different components of risk-for example by lowering social vulnerability versus decreasing the probability and degree of structural damage during a storm event. This has the potential to streamline approaches to risk management by clearly identifying the strategy with the greatest influence, or identifying potentially redundant strategies.

Because ISBUs offer a flexible temporary housing solution in that units can be repurposed or reused, an impact density curve could be paired with an assessment of general disaster risk or the impact potential of a specific 
disaster risk intervention strategy to help decision makers determine the most efficient temporary housing strategy for a specific region. We are aware of only one other methodology (Hennequin et al. 2018) that has used a similar means of assessing relative impact between two disaster risk management strategies, but we identify significant potential in studies of this type. In this way, impact density curves could be useful tools in the multi-criteria frameworks presented in Sect. 1.

Second, the spatial impact distribution map (Fig. 5) offers many possible applications to disaster risk management. One key use is as a tool for prioritizing areas where risk management resources and risk mitigation measures should be focused. Reducing risk first in areas of highest impact brings down the cumulative impact level of the entire city at a greater rate than if resources are concentrated in areas where the impact is relatively low. In this way, the spatial impact distribution map and the impact density curve can be used in tandem for risk management policy assessment. Comparing counties at the state or national level using population density and relative social vulnerability, policymakers can anticipate which counties are likely to be most at risk to a hurricane event and allocate resources pre- or post-hazard in accordance with anticipated need.

Such a tool serves to address criticism of sustainability practices (for example, promoting photovoltaics or replacing compact fluorescent light bulbs) that target individual residences, rather than communities at large, and divert resources from social problems such as poverty or chronic unemployment (Gotham and Campanella 2013). By considering sustainability at a broader, more holistic scale that includes risk, social vulnerabilities can be addressed through action on climate.

\section{Conclusion}

The increasing risk and exposure of people and assets to natural hazards and disasters due to population growth, development, and a changing climate suggest increasing need for temporary housing following natural hazards and potentially other types of hazards (for example, war, pandemics). Assessment of temporary housing need at the urban scale is lacking in the field of disaster risk management, including accurate estimations of displacement period. This study addresses these gaps in practice and literature, evaluating the total risk of environmental impact from temporary housing deployment in New Orleans for a range of hurricane intensities. The main conclusions of this study are summarized as:
- Assessment of hazard impact at the urban scale is needed to effectively conduct disaster risk management planning and mitigation. This includes accurate assessments of temporary housing need and displacement periods that include measures of social vulnerability. The current practice of determining displacement period by hazard severity alone is inadequate;

- An approach that combines risk assessment and life cycle assessment provides tools to politicians and disaster risk professionals to plan where to invest resources to decrease social vulnerability, thus enhancing resilience and adaptive capacity in a more homogeneous way at the urban scale. These tools can likewise be used to assess preparedness against increasing hurricane activity and intensity due to climate change, or to assess impact of temporary housing deployment for any number of other disasters. This framework also supports comparison of risk management strategies including tradeoffs between property damage and precedent risk intervention strategies;

- Temporary housing reuse is supported by the research findings; our approach can show the benefit is significant to minimizing the material impacts of relief housing deployment, particularly over an extended time horizon (for example, a 50-year planning period); and

- The most efficient strategy to reduce material impacts of temporary housing deployment after reuse is a design that minimizes concrete foundations.

Future work should use a similar approach to estimate the environmental impacts of (1) several types of temporary housing construction; (2) viable site locations; and (3) various risk management strategies to allow disaster risk management stakeholders to invest in hurricane preparedness concerning temporary housing that can minimize the global warming potential and energy demand when in use.

Open Access This article is licensed under a Creative Commons Attribution 4.0 International License, which permits use, sharing, adaptation, distribution and reproduction in any medium or format, as long as you give appropriate credit to the original author(s) and the source, provide a link to the Creative Commons licence, and indicate if changes were made. The images or other third party material in this article are included in the article's Creative Commons licence, unless indicated otherwise in a credit line to the material. If material is not included in the article's Creative Commons licence and your intended use is not permitted by statutory regulation or exceeds the permitted use, you will need to obtain permission directly from the copyright holder. To view a copy of this licence, visit http://creativecommons. org/licenses/by/4.0/.

\section{References}

Arslan, H. 2007. Re-design, re-use and recycle of temporary houses. Building and Environment 42(1): 400-406. 
Arslan, H., and N. Cosgun. 2008. Reuse and recycle potentials of the temporary houses after occupancy: Example of Duzce, Turkey. Building and Environment 43(5): 702-709.

Atmaca, N. 2017. Life-cycle assessment of post-disaster temporary housing. Building Research \& Information 45(5): 524-538.

Atmaca, A., and N. Atmaca. 2016. Comparative life cycle energy and cost analysis of post-disaster temporary housings. Applied Energy 171: 429-443.

Blake, E.S., C.W. Landsea, and E.J. Gibney. 2011. The deadliest, costliest, and most intense United States tropical cyclones from 1851 to 2010 (and other frequently requested hurricane facts). NOAA Technical Memorandum NWS NHC-6. Miami, FL: National Weather Service and National Hurricane Center.

Burton, C.G. 2010. Social vulnerability and hurricane impact modeling. Natural Hazards Review 11(2): 58-68.

Christensen, P., and E. Worzala. 2010. Teaching sustainability: Applying studio pedagogy to develop an alternative posthurricane housing solution using surplus shipping containers. Journal of Sustainable Real Estate 2(1): 335-360.

CIBSE (Chartered Institute of Building Service Engineers). 2006. Degree days: Theory and application. Technical Memorandum 41. London: CIBSE.

City-data. 2017. New Orleans, Louisiana neighborhood mapIncome, house prices, occupations, boundaries. http://www. city-data.com/nbmaps/neigh-New-Orleans-Louisiana.html Accessed 12 Mar 2017.

Colten, C.E., R.W. Kates, and S.B. Laska. 2008. Three years after Katrina: Lessons for community resilience. Environment 50(5): $36-47$.

Cutter, S.L., B.J. Boruff, and W.L. Shirley. 2003. Social vulnerability to environmental hazards. Social Science Quarterly 84(2): 242-261.

Data Center. 2017. Neighborhood statistical area data profiles. http:// www.datacenterresearch.org/data-resources/neighborhood-data/. Accessed 12 Mar 2017.

EIA (Energy Information Administration). 2018. Louisiana State energy profile. US states: State profiles and energy estimates. https://www.eia.gov/state/print.php?sid=LA. Accessed $18 \mathrm{Apr}$ 2017.

Elliott, J.R., and J. Pais. 2006. Race, class, and Hurricane Katrina: Social differences in human responses to disaster. Social Science Research 35(2): 295-321.

Esri (Environmental Systems Research Institute). 2015. Katrina 10: A decade of change in New Orleans. Story maps. https://story. maps.arcgis.com/apps/MapSeries/index.html?appid= 597d573e58514bdbbeb53ba2179d2359. Accessed 10 Feb 2017.

Finch, C., C.T. Emrich, and S.L. Cutter. 2010. Disaster disparities and differential recovery in New Orleans. Population and Environment 31(4): 179-202.

Fuller, M. 2006. Strong, affordable storm-ready housing project: Building with steel shipping containers and Super Therm. http:// www.eaglecoatings.net/content/supertherm/pdfs/Container_ Homes_Bob_Vila.pdf. Accessed 10 Feb 2017.

Gotham, K.F., and R. Campanella. 2013. Constructions of resilience: Ethnoracial diversity, inequality, and post-Katrina recovery, the case of New Orleans. Social Sciences 2(4): 298-317.

Gotham, K.F., and R. Campanella. 2011. Coupled vulnerability and resilience: The dynamics of cross-scale interactions in postKatrina New Orleans. Ecology and Society 16(3): 25-31.

Hennequin, T., H.J.D. Sørup, Y. Dong, and K. Arnbjerg-Nielsen. 2018. A framework for performing comparative LCA between repairing flooded houses and construction of dikes in nonstationary climate with changing risk of flooding. Science of The Total Environment 642: 473-484.

Hosseini, S.M.A., A. de la Fuente, and O. Pons. 2016. Multicriteria decision-making method for sustainable site location of post- disaster temporary housing in urban areas. Journal of Construction Engineering and Management 142(9): Article 04016036.

ICE (Inventory of Carbon and Energy). 2011. ICE database version 2.0. https://www.carbonsolutions.com/Resources/ICE\%20V2. 0\%20-\%20Jan\%202011.xls. Accessed 27 Mar 2017.

IEA (International Energy Agency). 2012. $\mathrm{CO}_{2}$ emissions from fuel combustion 2012. Paris: OECD Publishing.

IOS (International Organization for Standardization). 2006. Environmental management-Life cycle assessment-Principles and framework (ISO14040:2006). Geneva, Switzerland: International Organization for Standardization.

IPCC (Intergovernmental Panel on Climate Change). 2014. Climate change 2014: Impacts, adaptation, and vulnerability. Part B: Regional aspects. Contribution of working group II to the fifth assessment report of the Intergovernmental Panel on Climate Change. New York: Cambridge University Press.

Islam, H., G. Zhang, S. Setunge, and M.A. Bhuiyan. 2016. Life cycle assessment of shipping container home: A sustainable construction. Energy and Buildings 128: 673-685.

Ismail, F.Z., A. Halog, and C. Smith. 2017. How sustainable is disaster resilience? An overview of sustainable construction approach in post-disaster housing reconstruction. International Journal of Disaster Resilience in the Built Environment 8(5): $555-572$.

Johnson, C., G. Lizarralde, and C.H. Davidson. 2006. A systems view of temporary housing projects in post-disaster reconstruction. Construction Management and Economics 24(4): 367-378.

Jordan, E., A. Javernick-Will, and B. Amadei. 2014. A qualitative comparative analysis of neighborhood recovery following Hurricane Katrina. International Journal of Disaster Resilience in the Built Environment 5(4): 391-412.

Myers, C.A., T. Slack, and J. Singelmann. 2008. Social vulnerability and migration in the wake of disaster: The case of Hurricanes Katrina and Rita. Population and Environment 29(6): 271-291.

NASA/GISS (The National Aeronautics and Space Administration/ Goddard Institute for Space Studies). 2014. NASA-GISS: GISSE2-H model output prepared for CMIP5 historicalMisc, served by ESGF. WDCC at DKRZ. https://doi.org/10.1594/wdcc/ cmip5.gighhm.

Nigg, J.M., J. Barnshaw, and M.R. Torres. 2006. Hurricane Katrina and the flooding of New Orleans: Emergent issues in sheltering and temporary housing. The ANNALS of the American Academy of Political and Social Science 604(1): 113-128.

Peña, J. A., and K. Schuzer. 2012. Design of reusable emergency housing relief units using general purpose (GP) shipping containers. International Journal of Engineering Research and Innovation 4(2): 55-64.

Quarantelli, E.L. 1995. Patterns of sheltering and housing in US disasters. Disaster Prevention and Management: An International Journal 4(3): 43-53.

Song, Y., N. Mithraratne, and H. Zhang. 2016. Life-time performance of post-disaster temporary housing: A case study in Nanjing. Energy and Buildings 128: 394-404.

Tucker, S., A. Gamage, and C. Wijeyesekera. 2014. Some design aspects of sustainable post-disaster housing. International Journal of Disaster Resilience in the Built Environment 5(2): 163-181.

US DHS (United States Department of Homeland Security) and FEMA (Federal Emergency Management Agency). 2009. National disaster housing strategy. Washington, DC: Federal Emergency Management Agency.

US DHS (United States Department of Homeland Security) and FEMA (Federal Emergency Management Agency, Mitigation Division). 2015. Hurricane model Hazus-MH 2.1 technical manual. Washington, DC: Federal Emergency Management 
Agency. https://www.fema.gov/media-library/assets/documents/ 24609. Accessed 12 Mar 2017.

Zhang, G., S. Setunge, and S. van Elmpt. 2014. Using shipping containers to provide temporary housing in post-disaster recovery: Social case studies. Procedia Economics and Finance 18: 618-625. 